This is an unedited manuscript published in the Journal of Career Development.

Please note that the published version underwent minor additional editing in style and content.

Complete reference:

Zhang, C., Hirschi, A., Li, M., \& You, X. (2021). Profiles of calling and their relation to university-to-work transition outcomes. Journal of Career Development.

\title{
Profiles of Calling and Their Relation to University-to-Work Transition Outcomes
}

Chunyu Zhang ${ }^{1}$, Andreas Hirschi ${ }^{2}$, Mengzhu Li ${ }^{1}$, and Xuqun You ${ }^{1}$

1 School of Psychology, Shaanxi Normal University, Xi'an, China

2 Institute of Psychology, University of Bern, Switzerland

Author Note

Acknowledgement: This research was supported by National Natural Science Foundation of China (71702092); the Humanity and Social Science Foundation of Ministry of Education of China (17XJC190008); and Shaanxi Province Postdoctoral Science Foundation (2017BSHYDZZ55).

Address all correspondence about this manuscript to Chunyu Zhang, School of Psychology, Shaanxi Normal University, Xi’an, China, chunyu.zhang@snnu.edu.cn 


\begin{abstract}
In this study, we adopted a person-centered approach using latent profile analysis to explore whether profiles of calling based on the internal and external sources of a calling are identified and how these profiles relate to successful university-to-work transition outcomes (i.e., higher career satisfaction, higher person-job fit, and lower turnover intentions). We assessed a sample of 684 Chinese university graduates one week before and six months after graduation and found five profiles of calling: Strongly undeveloped calling, moderately undeveloped calling, transcendent calling, highly transcendent calling, and modern calling. We found that a calling which was driven by internal and external sources (i.e., transcendent calling) or predominantly by internal sources (i.e., modern calling) related to more successful university-to-work transition outcomes. Our findings contribute to the literature on calling by showing that the sources of calling are important to conceptualize different types of calling and differentiate the role of different callings.
\end{abstract}

Keywords: Calling profiles, sources of calling, university to work transition, latent profile analysis, career satisfaction 


\section{Profiles of Calling and Their Relation to University-to-Work Transition Outcomes Introduction}

The notion that individuals can view work as a calling has gained increased attention in recent years (Duffy \& Dik 2013; Thompson \& Bunderson, 2019). Calling represents a career orientation that ties one's personal meaning of work with a tendency of helping others or contributing to society, and which stems from an internal (e.g., inner passion) or external force (e.g., higher power, Duffy \& Dik 2013; Zhang, Dik, Wei, \& Zhang, 2015). Research has repeatedly demonstrated that calling is associated with positive career, work, and well-being outcomes (for a review, see Duffy \& Dik 2013; Thompson \& Bunderson, 2019). Moreover, callings are already present among university students and research suggests that callings might have important effects for early career development (e.g., Hirschi \& Herrmann, 2013).

Although prior research has offered important insights on the role of calling, there are still important issues to address. Research on the role of calling to date has predominantly used variable-centered approaches (e.g., regression analyses), focusing on degree of calling on average relates to other variables while largely ignoring the possibility that different types of calling may exist and affect career and work outcomes differently (Dik \& Shimizu, 2019; Shimizu, Dik, \& Conner, 2019). Scholars have conceptualized that callings are driven by multiple sources (Duffy \& Dik, 2013), which may result in distinct types of calling. Notably, Thompson and Bunderson (2019) proposed that calling can be categorized into four types based on whether it is driven by inner or outer requiredness (i.e., the source of calling): job or career (low on both inner and outer requiredness), neoclassical calling (low on inner but high on outer requiredness), modern calling (high on inner but low on outer requiredness), and transcendent calling (high on both inner and outer requiredness). Similarly, Dik and Shimizu (2019) proposed that calling can be conceptualized in a continuum of neoclassical to modern based on whether it is internally or externally driven. Yet, little is known if these types of calling are empirically distinguishable from each other and how they might differently relate to career outcomes. Accordingly, in the present study, we adopt the framework of Thompson and Bunderson (2019) to explore whether different types of calling based on their driving sources exist and how they related to university-to-work transition outcomes differently via the person-centered approach of latent profile analysis (LPA). We focus on university-to- 
work outcomes because research on the role of calling has been predominately conducted among university students or working samples separately (Duffy \& Dik 2013). Hence, little is known of the role of callings in career transitions, such as from university to work. This thus limits our understanding of how callings might facilitate successful career development across major career stages. Accordingly, we explore whether profiles of calling at university differentially relate to career and work outcomes after graduation.

To investigate these issues, we conducted a time-lagged study among a sample of Chinese university students who were undergoing the transition from university to work. We investigate Chinese university students in this context for two primary reasons. First, the sources of calling in a Chinese context were found to be somewhat different from the sources in a Western context (Zhang, Dik, et al., 2015). Thus, it is necessary to understand how the sources of calling might affect the perception of calling in a Chinese context. This corresponds to the general call for more research on calling in non-Western context (Duffy \& Dik 2013) and for examining the generalizability of calling research (Thompson \& Bunderson, 2019). Second, the transition from university to work is crucial and challenging for Chinese university students. The significant increase in the number of university graduates in the last decades (Ministry of Education of China, 2019) has to increased pressures to find satisfying employment (Zhou, Leung, \& Li, 2012). As such, it is significant to explore how different types of calling facilitate Chinese university students' transition to work life.

Our study makes several contributions to the literature. First, we adopt a personcentered approach to understand how different profiles of calling emerge based on its sources. This advances the notion that sources of calling are important to conceptualize distinct types of calling (Dik \& Shimizu, 2019; Thompson \& Bunderson, 2019) and thus broaden prior findings with variable-centered approaches. Second, our study extends the calling literature by focusing on the role of callings in a major career transition (i.e., from university to work), thereby contributing to a better understanding of the relevance of calling and its types. Finally, this study adds to the literature of understanding calling in a non-Western context.

\section{The Sources of Calling in Western and Chinese Contexts}

As a central component of calling, the driving sources of calling have long been recognized to be important to define a calling (Thompson \& Bunderson, 2019). For example, 
Hall and Chandler (2005) distinguished two views: a religious view in which a calling stems from God or a higher being, and a secular view in which the sources of calling are within the individual. Moreover, Hunter, Dik, and Banning (2010) identified several specific sources of calling, such as God's will, fulfilling destiny, God's gifts, an outside force, or a unique purpose. These sources of calling were typically categorized into two aspects: internal and external. Specifically, internal sources included intrinsic interest, inner passion, or inner voice (Duffy \& Dik 2013; Thompson \& Bunderson, 2019). By comparison, external sources consist of God, obligation, or a need in the world (Duffy \& Dik 2013; Thompson \& Bunderson, 2019). However, scholars tended to emphasize different sources in their specific definitions of calling. Notably, in Dobrow and Tosti-Kharas's (2011) definition, they proposed that calling stems from an inner source, a consuming and meaningful passion. In another influential definition, Dik and Duffy (2009) emphasized more external summons as the source of calling, such as needs of society, a family legacy, or needs of one's country. Accordingly, different definitions and measures of calling essentially focused on different driving sources.

In Chinese context, the classification of internal and external sources also emerged when defining a calling (Zhang, Dik, et al., 2015). However, the content of external sources in the Chinese context showed significant differences from those in a Western context. For example, Chinese individuals' callings typically are not perceived to be stemming from God or any other religious source. Notably, needs of society or nation is the salient external source of calling in China (Zhang, Dik, et al., 2015). This may be rooted in China's collectivist values. Particularly before the reform and open policy introduced in 1978, a calling was most likely perceived as issued by the Great Chairman Mao, the Communist Party, or the country (Zhou, Lv, \& Wang, 1991). Any job that is assigned to a person by the Party is a lofty calling because doing the job contributes to establishing socialism and achieving Communism (Zhao, 1984). Individuals were expected to sacrifice their personal interests and pursuits to satisfy the call of society and country. Moreover, Confucianism emphasizes accepting and fulfilling a duty stemming from family. This refers to filial piety which has been highly valued in Chinese culture for centuries (Zhou et al., 2012). In a Chinese context, work achievement offers a key path for honoring one's ancestors (Zhou et al., 2012). Research found that some Chinese university students viewed calling as a career that they have to accept because of 
fulfilling their family's will (Zhang, Dik, et al., 2015). Thus, the duty or expectation from family is another important external source of calling in Chinese populations.

The internal sources of calling in a Chinese context are generally similar to those in a Western context. That is, Chinese individuals' callings were also driven by inner passion, deepened interest, or inner conviction (Zhang, Dik, et al., 2015). The salience of these internal sources of calling may benefit from a series of economic and educational reforms in China for the last 40 years, such as starting the reform and open policy in 1978, shifting from planned economy to market economy since 1992, and expanding university enrollments since 1999 (Zhou et al., 2012). China's younger generations increasingly have more freedom to explore the selves, choose their educations, and follow their interests (Wang, 2006). They have changed their view of job and career, becoming more internal-oriented and self-directed in their career choice and development (Yan, 2010; Zhou et al., 2012). Thus, nowadays, some Chinese university students' callings may be more saliently driven by internal sources.

\section{Exploring Calling Profiles via Its Sources}

Prior research on calling has showed that source of calling may be important to identify different types of calling. For example, Hirschi (2011) found a type of calling that endorsed a close connection with religion and is motivated by prosocial intentions. This type of calling is also supported by Shimizu, Dik, and Conner (2019). In another study of American employed adults, Duffy, Allan, Bott, and Dik (2014) examined three groups individuals with different sources of calling: external summons, destiny, and perfect fit, and found no significant differences of them on living a calling, job satisfaction, and life satisfaction.

In the present study, we adopt the conceptual framework of Thompson and Bunderson (2019) which helps to integrate the diverse approaches to define a calling and its sources by distinguishing callings according to their inner and outer requiredness (i.e., sources of calling) as two orthogonal dimensions. According to this framework, callings can theoretically be classified into four distinct types: (1) job or career, characterized as low on both inner and outer requiredness, largely corresponding to the job or career orientation from the classification of Wrzesniewski, McCauley, Rozin, \& Schwartz (1997) that prioritizes financial rewards or career advancement; (2) neoclassical calling, characterized as high on outer 
requiredness but low on inner requiredness, corresponding to the definition of Bunderson and Thompson (2009); (3) modern calling, characterized as high on inner requiredness but low on outer requiredness, such as the definition of Dobrow and Tosti-Kharas (2011); and (4) transcendent calling, characterized as high on both inner and outer requiredness. Thompson and Bunderson (2019) proposed that even if the sources of calling were expressed differently across cultures or contexts, the experience of calling as a match between inner and outer requiredness is a universal human experience and may occur across cultures and contexts. Thus, we adopt this framework and test whether profiles of calling based on its internal and external sources emerge among Chinese university students. Similarly, we posit that at least four profiles of calling may exist: (1) undeveloped calling, similar to job or career orientation (Wrzesniewski et al.,1997), in which the levels of internal sources and external sources are all low. Undeveloped callings may exist because some Chinese university students may simply not have a sense of calling (Zhang, Dik, et al., 2015); (2) neoclassical calling, in which the levels of external sources are moderate or high, whereas internal sources are low. Such a type of calling might reflect the influence of Chinese collectivism and Confucian values (Zhang, Dik, et al., 2015), leading to a strong external source for a calling; (3) modern calling, in which the levels of internal sources are moderate or high, whereas external sources are low. This type of calling might exist because internal sources are becoming more salient among the Chinese younger generation (Yan, 2010; Zhou et al., 2012); finally (4) transcendent calling, in which the levels of internal sources and external sources are all moderate or high. This type would thus represent university students who have achieved a congruence between internal and external sources of their callings.

Hypothesis 1: Four profiles of calling exist: (1) undeveloped calling, (2) neoclassical calling, (3) modern calling, and (4) transcendent calling.

\section{Outcomes of Calling Profiles in Successful Transition to Work}

The second aim of our study is to examine whether different types (i.e., profiles) of calling show unique relations with outcomes of a successful transition from university to work. We consider three important indicators of a successful transition: higher career satisfaction, higher perceived person-job fit, and lower turnover intentions. These indicators were considered to be typical university-to-work transition outcomes because they signal the 
self-perceived quality of job and career after graduation (Wendlandt \& Rochlen, 2008; Sortheix, Chow, \& Salmela-Aro, 2015). Research on calling has demonstrated that a calling is positively related to these indicators, such as higher career satisfaction (Dobrow \& TostiKharas, 2011; Zhang, Hirschi, Herrmann, Wei, \& Zhang, 2015), higher person-job fit (Hirschi, 2012), and lower turnover intention (Duffy, Dik, \& Steger, 2011). However, none of these associations was tested in the transition from university to work.

Based on self-determination theory (Gagné \& Deci, 2005), we posit that these indicators are especially salient for university students who have a transcendent calling or modern calling. Specifically, self-determination theory (Gagné \& Deci, 2005) implies that autonomous motivations (i.e., intrinsic or internal motivations) are related to greater wellbeing and satisfaction in work than controlled motivations (i.e., extrinsic or external motivations). Indeed, research has supported that more autonomous motivations are associated with higher job satisfaction, higher perceived fit, and lower turnover intentions (e.g., Breaugh, Ritz, \& Alfes, 2017; Kuvaas, Buch, Weibel, Dysvik, \& Nerstad, 2017; Sortheix et al., 2015). Because the internal sources of calling reflect a more autonomous motivation and external sources a more controlled motivation, calling profiles which are driven more by internal sources may relate to more successful transition outcomes than calling profiles driven by external sources. In this regard, the effects of a modern calling on transition outcomes may be more positive than those of a neoclassical calling. However, the most positive effects might be achieved by the simultaneous presence of internal and external sources, such as in a transcendent calling (Bunderson \& Thompson, 2019). This is because research shows that combining autonomous and controlled motivation is most beneficial to positive workplace outcomes (Howard, Gagné, Morin, \& Van den Broeck, 2016). Finally, university students with undeveloped calling may exhibit less successful transition outcomes than those with other types of calling because research has found that individuals with a job or career orientation have lower job/work satisfaction than employees a calling orientation (Wrzesniewski et al., 1997; Willner, Lipshits-Braziler, \& Gati, 2020).

Hypothesis 2: University graduates in the transcendent calling profile exhibit the highest career satisfaction, highest person-job fit, and lowest turnover intentions after 
graduation, followed by university graduates in the modern calling profile, the neoclassical calling profile, and the undeveloped calling profile.

\section{Method}

\section{Participants and Procedure}

The data of this study were drawn from a larger project on calling among Chinese university graduates. Data were collected among two large universities in China. The survey of Time 1 (T1) was conducted at the end of June 2018, one week before graduation and included measure of sources of calling. Six months after graduation, we administered the second survey (T2). Because this study focused on the transition from university to work, we excluded participants who continued to full-time studying at T2. The surveys at T2 included measures of career satisfaction, person-job fit, and turnover intentions. To improve the response rate, we offered 10 China Yuan (CNY; equivalent to approximately \$1.50 USD) at $\mathrm{T} 1$ and $15 \mathrm{CNY}$ (equivalent to approximately \$2.20 USD) at T2 as an incentive to each participant who provided valid responses.

A total of 1,297 university students were invited, and 684 provided valid responses at $\mathrm{T} 1($ response rate $=53 \%) ; 44 \%(N=299)$ participated again and provided valid responses at T2. Most participants (74\%) self-identified as women. The sample reported a mean age of 23.05 years ( $S D=0.96$, ranging from 18 to 26 years) at $\mathrm{T} 1$, with $84 \%$ of participants majoring in medicine, and the remaining participants majored in mathematics. These two majors were selected because they are socially valued majors with a high reputation in China. We expect students in these majors may be particularly called by a force (either internal, external, or both) to pursue these majors. Moreover, because we were interested in the sources of calling, we verified that all included participants reported having a calling at least to some degree and reported a mean item score of $>1.91$ in the Chinese Calling Scale (Zhang, Herrmann, Hirschi, Wei, \& Zhang, 2015), ranging from 1 (strongly disagree) to 5 (strongly agree).

We tested the potential impact of "missingness" by creating a dummy variable that separated the participants who participated in both waves from those who participated in only the first wave (Little 2013). We found that missingness was nonsignificantly related to any of the study variables or demographic variables at $\mathrm{T} 1$.

\section{Measures}


Table 1 shows the reliability, means, and standard deviations for all measures.

Sources of calling. The internal and external sources of calling were assessed using items from Zhang, Dik, et al.'s (2015) qualitative findings in a Chinese context. Specifically, internal sources of calling were measured by two items with the item-stem "I have a calling to a certain career because...": "I feel an extreme passion to it" and "I have an inner conviction in it". External sources of calling were assessed by three items with the same item-stem: "I respond to the needs of society", "I answer the duty of my country", and "I need to fulfill the expectation and duty of my family". The response scale ranged from 1 (strongly disagree) to 5 (strongly agree). We ran an exploratory factor analysis using principal axis factoring with oblique rotation to explore the structure of this measure. The results supported a two-factor structure. Items all highly loaded on their respective factors with low cross-loadings on the other factor $($ all $<.19)$. Factor loadings for the two items of internal sources were respectively .76 and .69 , and for the three items of external sources $.74, .70$, and .49 . Confirmatory factor analysis showed that the two-factor structure fit to the data well $\left(\mathrm{S}-\mathrm{B} \chi^{2}=7.02 ; d f=4 ; \mathrm{CFI}=\right.$ $1.0 ; \mathrm{TLI}=.99 ; \mathrm{RMSEA}=.03 ; \mathrm{SRMR}=.02)$ and significantly better $(p<.001)$ than a onefactor structure in which all items loaded on one latent factor $\left(\mathrm{S}-\mathrm{B} \chi^{2}=81.01 ; d f=5 ; \mathrm{CFI}=\right.$ $.88 ; \mathrm{TLI}=.77 ; \mathrm{RMSEA}=.15 ; \mathrm{SRMR}=.07)$.

Career satisfaction. We used a Chinese language version of the five-item Career Satisfaction Scale (Greenhaus, Parasuraman, \& Wormley, 1990; Pan, Sun, \& Chow, 2011). Participants answered on a five-point scale ranging from 1 (strongly disagree) to 5 (strongly agree). An example item is, "I am satisfied with the success I have achieved in my career." Zhang, Hirschi, et al. (2015) reported a Cronbach's alpha of .92 in Chinese employees.

Person-job fit. We used the Chinese language version (Astakhova, Doty, \& Hang, 2014) of the scale developed by Cable and DeRue (2002) to measure person-job fit (i.e., demands-abilities fit) with three items (e.g., "The match is very good between the demands of my job and my personal skills." All items were answered on a five-point scale ranging from 1 (strongly disagree) to 5 (strongly agree). Cable and DeRue (2002) reported the subscale's good internal consistency $(\alpha=.84-.89)$. In studies based on Chinese employee samples, the scale was found to have good reliability ( $\alpha=.78$ - .95; Astakhova et al., 2014; Han, Chiang, McConville, \& Chiang, 2015) and construct validity (Astakhova et al., 2014). 
Turnover intentions. We used three items in Chinese derived from Hui, Wong, and Tjosvold (2007) to assess participants' intention to leave their job. An example item is, "It is very possible that I will look for a new job next year.” The response scale ranged from 1 (strongly disagree) to 5 (strongly agree). Hui et al. (2007) reported an acceptable reliability of this scale in Chinese employee sample $(\alpha=.60)$.

Control variables. We considered three demographic variables (i.e., gender, age, and study major) that could affect participants' calling and transition from university to work (e.g., Dobrow \& Tosti-Kharas, 2011; Lu, Sun, \& Du, 2016). However, age and study major were not found to relate to any of the study variables. Male was positively related to career satisfaction $(r=.14, p<.05)$, and person-job fit $(r=.14, p<.05)$. However, controlling for these three variables did not change the results of relating calling profiles to university-towork transition outcomes. Thus, to increase power and interpretability of the results, we excluded them from the reported analyses.

\section{Analytical Approach}

We used LPA analysis in Mplus (version 7, Muthén \& Muthén 1998-2012) to explore calling profiles. LPA aims to find meaningful subgroups/profiles of people that represent similar patterns in measured continuous variables (Tein, Coxe, \& Cham, 2013). To decide on the number of profiles, several fit statistics were considered (Nylund, Asparouhov, \& Muthén, 2007; Tein et al., 2013). First, Akaike's Information Criterion (AIC), Bayesian Information Criterion (BIC), and sample-size adjusted BIC (SABIC) are commonly used for model selection (Tein et al., 2013). Lower AIC, BIC and SABIC indicate a better profile solution. Second, two likelihood ratio statistic tests were conducted, the Lo-Mendell-Rubin adjusted likelihood ratio test (LRT) and bootstrap likelihood ratio test (BLRT) (Nylund et al., 2007; Tein et al., 2013). A significant probability value (e.g., $p<.05)$ indicates that the $k$-profiles solution provides better fit to the observed data than the $k-1$ profiles solution. Third, entropy was considered to evaluate the classification accuracy. A higher value of entropy indicates a better profile solution (Tein et al., 2013). Finally, we additionally considered whether the suggested profile solution is theoretically meaningful.

After obtaining the most appropriate number of calling profiles, we tested how these profiles relate to outcomes of a successful transition from university to work by including 
auxiliary variables with the DU3STEP command in Mplus (Asparouhov \& Muthén, 2014). To address missingness, we adapted a full information maximum likelihood (FIML) which was recommended to properly estimate the missing data (Little, 2013).

\section{Results}

\section{Identifying Distinct Profiles of Callings}

We specified LPA models ranging from 2 to 6 profiles. Table 2 presents their fit indices and likelihood ratio statistic tests. As shown, AIC, BIC, and SABIC dramatically declined until the 5-profile model and entropy was the highest for 5-profile model, suggesting that 5-profile model may be the best solution. The 6-profile and 7-profile models were not significantly different from 5-profile model (i.e., $\triangle \mathrm{AIC}<10, \triangle \mathrm{SABIC}<10$, LRT $p>.05$ ). These profile models were thus rejected. Based on these considerations, the 5-profile model was selected as the best solution, with second lowest AIC, lowest BIC, lowest SABIC, highest entropy value, and theoretically meaningful classifications.

As shown in Table 3 and Figure 1, the first class included 50 (7\%) participants, characterizing a strongly undeveloped calling profile, in which the levels of internal sources and external sources were the lowest compared to other profiles. The second profile included $326(48 \%)$ participants, characterizing a moderately undeveloped calling profile, in which the levels of internal sources and external sources were all moderate but somewhat below the sample average. The third profile included 27 (4\%) participants, characterizing a modern calling profile, in which the levels of internal sources were high, but external sources were low. The fourth profile included 252 (37\%) participants, characterizing a transcendent calling profile, in which the levels of internal sources and external sources were all higher than the sample mean. The fifth and last profile included 29 (4\%) participants, characterizing a highly transcendent calling profile, in which the levels of internal sources and external sources were the highest compared to all other profiles and clearly above the sample mean. These results partly supported Hypothesis 1 as we confirmed the existence of five distinct calling profiles. However, we did not find a classification of neoclassical calling profile.

\section{Testing Outcomes of Calling Profiles}

We then applied the DU3STEP command in Mplus by including auxiliary variables for testing the relation between calling profiles and successful university-to-work transition 
outcomes. We found significant differences among the five profiles on career satisfaction, person-job fit, and turnover intentions. As shown in Table 3, university graduates with a highly transcendent calling or transcendent calling exhibited higher career satisfaction than those with a strongly undeveloped calling. University graduates with a transcendent calling or modern calling exhibited significantly higher person-job fit than those with strongly undeveloped calling and moderately undeveloped calling profiles. University students with a transcendent calling, modern calling, or moderately undeveloped calling exhibited significant lower turnover intentions than those with strongly undeveloped calling profile. Thus, these results partly supported Hypothesis 2 by showing generally more positive effects for transcendent calling and modern calling profiles compared to other calling profiles on successful university-to-work transition outcomes.

\section{Discussion}

The purpose of this study was to explore if different profiles of calling based on its sources exist and how such calling profiles relate to university-to-work transition outcomes (i.e., higher career satisfaction, higher perceived person-job fit, and lower turnover intentions). By using a person-centered approach with LPA analysis, we identified different calling profiles. We found significant differences among these profiles on successful university-to-work transition outcomes. Transcendent and modern callings showed a greater association with successful university-to-work transition indicators than other profiles. These findings add notable insights to the literature of calling in several important ways.

First, our findings support the emerging notion that different types of calling exist with potentially different implications for career development (Thompson \& Bunderson, 2019; Dik \& Shimizu, 2019). By considering callings' internal and/or external sources, we found five profiles of calling, with one profile that endorsed low levels of internal sources and external sources (strongly undeveloped calling), one that endorsed moderate levels of internal sources and external sources (moderately undeveloped calling), one that exhibited high levels of internal sources and external sources (transcendent calling), one that endorsed very high levels of internal sources and external sources (highly transcendent calling), and one that emphasized more on internal sources but less on external sources (modern calling). Our findings add to prior research in which different calling profiles were found (e.g., Hirschi, 
2011; Shimizu et al., 2019). More importantly, our results partly support the framework of Thompson and Bunderson (2019), which distinguishes transcendent calling and modern calling. Although our identified profiles of undeveloped callings are not directly identical with the job or career orientation suggested in their classification, our findings suggest that a low calling which is not sufficiently motivated by internal or external sources exists for many Chinese students. It is possible that these students have more of a job or career orientation towards work. As we did not directly assess these alternative career orientations, it seems important for future research to examine how and if undeveloped callings are related to job or career orientations towards work. Moreover, nearly half of the participants exhibited a transcendent or highly transcendent calling, suggesting that majority of Chinese university students with callings were driven by both internal and external sources. However, unexpectedly, we did not find a profile of neoclassical calling as suggested in the classification of Thompson and Bunderson (2019). This implies that few Chinese university students have a calling exclusively driven by external sources. This is contrary to the expected influence of Chinese collectivism and Confucianism culture on the perception of a calling that is largely driven by external sources (e.g., duty of family, needs of society, Zhang, Dik, et al., 2015). Rather, our findings suggest that internal sources may be a leading driver of a calling, even in a Chinese context. However, could be that the external sources of calling get internalized (e.g., into an inner conviction) and thereby motivate a calling along with more internal sources (e.g., passion). In sum, these findings indicate that when defining a calling, it is important to consider whether callings are driven by internal or external sources as these types of calling seem to notably differ in prevalence.

Second, our findings suggest that profiles of calling have important implications for successful university-to-work transition. This extends prior research on calling which has largely ignored exploring the role of calling in critical career transition. Our study thus adds to still limited research base focusing on calling's role in salient career and life transitions (e.g., Dobrow \& Heller, 2015). Our results indicate that university graduates with a transcendent calling or a modern calling exhibited more favorable transition outcomes (i.e., higher career satisfaction, higher perceived person-job fit, and lower turnover intentions), compared with students exhibiting underdeveloped callings. Our results indicate that the sources of calling 
might be important to consider regarding their career effects. That is, callings which were driven by internal and external sources or predominantly by internal sources played a greater role for positive university-to-work transition outcomes. On the one hand, this supports the notion that the more beneficial form of calling may stem from a good match of inner requiredness with outer requiredness (Thompson \& Bunderson, 2019). In addition, our findings add to the literature of university-to-work transitions, suggesting that the perception of certain types of callings (i.e., transcendent or modern callings) can facilitate this transition.

\section{Limitations and Future Research}

First, our findings were based on a sample of Chinese university graduates majored in medicine and mathematics. We advocate more research on exploring profiles of calling based on its sources across diverse populations and cultures. Second, group sizes of the modern calling and highly transcendent calling profiles were relatively small. Thus, we advocate future research to use larger samples to explore the profiles of calling. Third, we did not measure participants' job status and career experience after transitioning to work life, such as their work positions, salaries, working hours, or job characteristics. Future research could consider these variables because they may potentially affect transition outcomes. Fourth, we did not address potential underlying mechanisms of explaining the relation between types of calling and transition outcomes (e.g., mediators and moderators, such as living a calling after graduation). Future research should explore the mechanism of such relations. Finally, we only measured transition outcomes at one time point - six months after graduation. We expect that this time lag is sufficient to meaningfully examine outcomes in the transition from university to work (Brown, Cober, Kane, Levy, \& Shalhoop, 2006). However, it is possible that shorter or longer time lags would lead to different results. Future research could use several pre- and post-transition time points to fully capture the role of calling during this transition.

\section{Practical Implications}

Our findings suggest that counselors and university students should realize the importance of calling's sources. It might thus not be sufficient to simply ascertain whether an individual has a sense of calling. Counselors should further help clients to discern where their callings stem from. Our results suggest that the ideal situation is that a calling is driven by internal sources or a good matching of internal sources with external sources. As our results 
indicate, such modern or transcendent calling predicts more successful university-to-work transition outcomes than other types of callings. Thus, counselors should be cognizant of the positive role of these calling sources in discerning a calling and achieving satisfying career outcomes. Career interventions aiming to explore the self, one's inner passion, or deepened interest - while understanding their association with a broader context (e.g., family or society) - could thus be used to help university students to discern and understand their callings. 


\section{References}

Asparouhov, T., \& Muthén, B. (2014). Auxiliary variables in mixture modeling: Three-step approaches using Mplus. Structural Equation Modeling, 21, 329-341. doi: 10.1080/10705511.2014.915181.

Astakhova, M. N., Doty, D. H., \& Hang, H. (2014). Understanding the antecedents of perceived fit at work in the United States, Russia, and China. European Management Journal, 32, 879-890. doi: 10.1016/j.emj.2014.03.005

Breaugh, J., Ritz, A., \& Alfes, K. (2017). Work motivation and public service motivation: disentangling varieties of motivation and job satisfaction. Public Management Review, 20(10), 1423-1443. doi:10.1080/14719037.2017.1400580

Brown, D. J., Cober, R. T., Kane, K., Levy, P. E., \& Shalhoop, J. (2006). Proactive personality and the successful job search: A field investigation with college graduates. Journal of Applied Psychology, 91, 717-726. doi: 10.1037/0021-9010.91.3.717

Bunderson, J. S., \& Thompson, J. A. (2009). The call of the wild: Zookeepers, callings, and the double-edged sword of deeply meaningful work. Administrative Science Quarterly, 54, 32-57. doi:10.2189/asqu.2009.54.1.32

Cable, D.M., \& De Rue, D.S. (2002). The convergent and discriminant validity of subjective fit perceptions. Journal of Applied Psychology, 87, 875-884. doi: 10.1037//00219010.87.5.875

Dik, B. J., \& Duffy, R. D. (2009). Calling and vocation at work: Definitions and prospects for research and practice. The Counseling Psychologist, 37, 424-450. doi:10.1177/0011000008316430

Dik, B. J., \& Shimizu, A. B. (2019). Multiple meanings of calling: Next steps for studying an evolving construct. Journal of Career Assessment, 27(2), 323-336. doi:10.1177/1069072717748676

Dobrow, S. R. \& Heller, D. (2015). Follow your heart or your head? A longitudinal study of the facilitating role of calling and ability in the pursuit of a challenging career. Journal of Applied Psychology, 100(3), 695-712. doi: 10.1037/a0038011

Dobrow, S. R., \& Tosti-Kharas, J. (2011). Calling: The development of a scale measure. Personnel Psychology, 64, 1001-1049. doi:10.1111/j.1744-6570.2011.01234.x 
Duffy, R. D., Allan, B. A., Bott, E. M., \& Dik, B. J. (2014). Does the source of a calling matter? External summons, destiny, and perfect fit. Journal of Career Assessment, 22(4), 562-574. doi:10.1177/1069072713514812

Duffy, R. D. \& Dik, B. J. (2013). Research on calling: What have we learned and where are we going? Journal of Vocational Behavior, 83, 428-436. doi: 10.1016/j.jvb.2013.06.006

Duffy, R. D., Dik, B. J., \& Steger, M. S. (2011). Calling and work related outcomes: Career commitment as a mediator. Journal of Vocational Behavior, 78, 210-218. doi: 10.1016/j.jvb.2010.09.013

Eisinga, R., Grotenhuis, M.T., \& Pelzer, B. (2013). The reliability of a two-item scale: Pearson, Cronbach, or Spearman-Brown? International Journal of Public Health, 58(4), 637-42. doi: 10.1007/s00038-012-0416-3

Gagné, M., \& Deci, E. L. (2005). Self-determination theory and work motivation. Journal of Organizational Behavior, 26(4), 331-362. doi:10.1002/job.322

Greenhaus, J. H., Parasuraman, S., \& Wormley, W. M. (1990). Effects of race on organizational experiences, job performance evaluations, and career outcomes. Academy of Management Journal, 33(1), 64-86. doi:10.5465/256352

Hall, D. T., \& Chandler, D. E. (2005). Psychological success: When the career is a calling. Journal of Organizational Behavior, 26, 155-176. doi:10.1002/job.301

Han, T. S., Chiang, H. H., McConville, D., \& Chiang, C. L. (2015). A longitudinal investigation of person-organization fit, person-job fit, and contextual performance: The mediating role of psychological ownership. Human Performance, 28(5), 425-439. doi: 10.1080/08959285.2015.1021048

Hirschi, A. (2011). Callings in career: A typological approach to essential and optional components. Journal of Vocational Behavior, 79(1), 60-73. doi: 10.1016/j.jvb.2010.11.002

Hirschi, A. (2012). Callings and work engagement: Moderated mediation model of work meaningfulness, occupational identity, and occupational self-efficacy. Journal of Counseling Psychology, 59, 479-485. doi: 10.1037/a0028949

Hirschi, A., \& Herrmann, A. (2013). Calling and career preparation: Investigating 
developmental patterns and temporal precedence. Journal of Vocational Behavior, 83(1), 51-60. doi:10.1016/j.jvb.2013.02.008

Howard, J., Gagné, M., Morin, A. J. S., \& Van den Broeck, A. (2016). Motivation profiles at work: A self-determination theory approach. Journal of Vocational Behavior, 95-96, 74-89. doi:10.1016/j.jvb.2016.07.004

Hui, C., Wong, A., Tjosvold, D. (2007). Turnover intention and performance in China: The role of positive affectivity, Chinese values, perceived organizational support and constructive controversy. Journal of Occupational and Organizational Psychology, 80, 735-751. doi:10.1348/096317906X171037

Hunter, I., Dik, B., \& Banning, J. (2010). College students' perceptions of calling in work and life: A qualitative analysis. Journal of Vocational Behavior, 83, 51-60. doi:10.1016/j.jvb.2009.10.008

Kuvaas, B., Buch, R., Weibel, A., Dysvik, A., \& Nerstad, C. G. L. (2017). Do intrinsic and extrinsic motivation relate differently to employee outcomes? Journal of Economic Psychology, 61, 244-258. doi:10.1016/j.joep.2017.05.004

Little, T. D. (2013). Longitudinal structural equation modeling. New York, NY: Guilford. Lu, C.-Q., Sun, J.-W., \& Du, D.-Y. (2016). The relationships between employability, emotional exhaustion, and turnover intention the moderation of perceived career opportunity. Journal of Career Development, 43(1), 37-51. doi:10.1177/0894845315576372

Ministry of Education of China. (2019). China expected to have 8.74 million college graduates in 2020. Retrieved December 29, 2019, from http://en.moe.gov.cn/news/media_highlights/201911/t20191101_406437.html

Muthén, B. O., \& Muthén, L. K. (1998-2012). Mplus user's guide. Seventh edition. Los Angeles, CA: Muthén \& Muthén.

Nylund, K. L., Asparouhov, T., \& Muthén, B. O. (2007). Deciding on the number of classes in latent class analysis and growth mixture modeling: A Monte Carlo simulation study. Structural Equation Modeling, 14(4), 535-569. doi:10.1080/10705510701575396

Pan, W., Sun, L. Y. and Chow, I. H. S. (2011). The impact of supervisory mentoring on personal learning and work outcomes: The duel moderating effect of self-efficacy. 
Journal of Vocational Behavior, 78(2), 264-273. doi: 10.1016/j.jvb.2010.05.001

Shimizu, A. B., Dik, B. J., \& Conner, B. T. (2019). Conceptualizing calling: Cluster and taxometric analyses. Journal of Vocational Behavior, 114, 7-18. doi:10.1016/j.jvb.2018.07.006

Sortheix, F.M., Chow, A., Salmela-Aro, K. (2015). Work values and the transition to work life: A longitudinal study. Journal of Vocational Behavior, 89, 162-171. doi: 10.1016/j.jvb.2015.06.001

Tein, J.-Y., Coxe, S., \& Cham, H. (2013). Statistical power to detect the correct number of classes in latent profile analysis. Structural Equation Modeling, 20(4), 640-657. doi:10.1080/10705511.2013.824781

Thompson, J. A., \& Bunderson, J. S. (2019). Research on work as a calling...and how to make it matter. Annual Review of Organizational Psychology and Organizational Behavior, 6, 421-443. doi:10.1146/annurev-orgpsych-012218-015140

Wang, Y. (2006). Value changes in an era of social transformations: college-educated Chinese youth. Educational Studies, 32(2), 233-240. doi:10.1080/03055690600631150

Wendlandt, N. M., \& Rochlen, A. B. (2008). Addressing the college-to-work transition: Implications for University career counselors. Journal of Career Development, 35(2), 151-165. doi: 10.1177/0894845308325646

Willner, T., Lipshits-Braziler, Y., \& Gati, I. (2020). Construction and initial validation of the Work Orientation Questionnaire. Journal of Career Assessment, 28(1), 109-127. doi:10.1177/1069072719830293

Wrzesniewski, A., McCauley, C., Rozin, P., \& Schwartz, B. (1997). Jobs, careers, and callings: People's relations to their work. Journal of Research in Personality, 31(1), 21-33. doi:10.1006/jrpe.1997.2162

Yan, Y. (2010). The Chinese path to individualization. The British Journal of Sociology, 61(3), 489-512. doi:10.1111/j.1468-4446.2010.01323.x

Zhao, S. (1984). Guiding the career value of young generation. China Youth Studies, 3, 52-57. Zhang, C., Dik, B. J., Wei, J., \& Zhang, J. (2015). Work as a calling in China: A qualitative study of Chinese college students. Journal of Career Assessment, 23(2), 236-249. doi: $10.1177 / 1069072714535029$ 
Zhang, C., Herrmann, A., Hirschi, A., Wei, J., \& Zhang, J. (2015). Assessing calling in Chinese college students: Development of a measure and its relation to hope. Journal of Career Assessment, 23(4), 582-596. doi: 10.1177/1069072715595804

Zhang, C., Hirschi, A., Herrmann, A., Wei, J., \& Zhang, J. (2015). Self-directed career attitude as predictor of career and life satisfaction in Chinese employees. Career Development International, 20(7), 703-716. doi: 10.1108/CDI-06-2015-0090

Zhou, S., Leung, S. A., \& Li, X. (2012). The meaning of work among Chinese university students: Findings from prototype research methodology. Journal of Counseling Psychology, 59, 408-423. doi:10.1037/a0028374

Zhou, C., Lv, X., \& Wang, G. (1991). Changes in the impression of college students in new China. China Youth Studies, 5, 29-32. 


\section{Table 1}

Correlations, Reliabilities, Means, and Standard Deviations of the Assessed Variables

\begin{tabular}{|c|c|c|c|c|c|c|c|}
\hline Variables & $M$ & $S D$ & 1 & 2 & 3 & 4 & 5 \\
\hline 1. Internal source of calling $\mathrm{T} 1$ & 3.49 & .74 & .71 & & & & \\
\hline 2. External source of calling $\mathrm{T} 1$ & 3.37 & .68 & $.46^{* *}$ & .72 & & & \\
\hline 3. Career satisfaction $\mathrm{T} 2$ & 3.45 & .78 & $.30 * *$ & $.19 * *$ & .93 & & \\
\hline 4. Person-job fit $\mathrm{T} 2$ & 3.35 & .71 & $.23 * *$ & $.13^{*}$ & $.47 * *$ & .86 & \\
\hline 5. Turnover intentions $\mathrm{T} 2$ & 2.78 & .79 & $-.22 * *$ & -.08 & $-.35 * *$ & $-.34 * *$ & .73 \\
\hline
\end{tabular}

Note. Numbers in diagonal in italic are the Cronbach's alpha reliability coefficients except for "internal sources of calling". For the two-item internal source of calling, Spearman-Brown coefficient is reported because it is recommended to best reflect reliability (Eisinga, Grotenhuis, \& Pelzer, 2013). T1 = Time 1: one week before graduation; T2 = Time 2: six months after graduation, $N_{T 1}=684, N_{T 2}=299$.

${ }^{*} p<.05, * * p<.01$. 


\section{Table 2}

Results of Latent Profile Analysis with Sources of Calling as Profile Indicators

\begin{tabular}{|c|c|c|c|c|c|c|c|c|c|}
\hline No. of profiles & LL & $\mathrm{FP}$ & Scaling & AIC & $\mathrm{BIC}$ & SABIC & LRT $p$ & BLRT $p$ & Entropy \\
\hline 2 & -1415.42 & 7 & 1.28 & 2844.85 & 2876.54 & 2854.32 & .00 & .00 & .47 \\
\hline 3 & -1394.20 & 10 & 1.15 & 2808.41 & 2853.69 & 2821.93 & .06 & .00 & .66 \\
\hline 4 & -1361.06 & 13 & 1.09 & 2748.11 & 2806.97 & 2765.70 & .00 & .00 & .83 \\
\hline 5 & -1338.81 & 16 & 1.10 & 2709.61 & 2782.06 & 2731.26 & .00 & .00 & .84 \\
\hline 6 & -1335.01 & 19 & 1.10 & 2708.01 & 2794.04 & 2733.71 & .25 & .27 & .80 \\
\hline 7 & -1330.28 & 22 & 1.13 & 2704.56 & 2804.18 & 2734.33 & .37 & .05 & .80 \\
\hline
\end{tabular}

Note: $N=684 . \mathrm{LL}=$ model log-likelihood; $\mathrm{FP}=$ number of free parameters; Scaling = scaling correction factor of the robust maximum likelihood estimator; AIC = Akaike's Information Criterion; BIC = Bayesian Information Criterion; SABIC = sample-size adjusted BIC; LRT $p=$ significance of Lo, Mendell, \& Rubin adjusted likelihood ratio test; BLRT $p=$ significance of bootstrap likelihood ratio test. 


\section{Table 3}

Characteristics for the Five Latent Profiles for Calling and Results of Regression Analyses Predicting Outcomes After Transitioning to Work

\begin{tabular}{|c|c|c|c|c|c|c|c|c|c|c|c|}
\hline \multirow[b]{2}{*}{ Latent Profiles } & \multirow[b]{2}{*}{$N(\%)$} & \multicolumn{2}{|c|}{ Internal sources $\mathrm{T} 1$} & \multicolumn{2}{|c|}{ External sources T1 } & \multicolumn{2}{|c|}{ Career satisfaction T2 } & \multicolumn{2}{|c|}{ Person-job fit T2 } & \multicolumn{2}{|c|}{ Turnover intentions T2 } \\
\hline & & $M$ & $S E$ & $M$ & $S E$ & $M$ & $S E$ & $M$ & $S E$ & $M$ & $S E$ \\
\hline 1. Strongly undeveloped & $50(7 \%)$ & 2.49 & .14 & 2.21 & .07 & $3.084,5$ & .21 & $3.05_{3,4}$ & .17 & $3.21_{2,3,4}$ & .17 \\
\hline 3. Modern & $27(4 \%)$ & 4.17 & .22 & 2.21 & .14 & 3.51 & .32 & $3.57_{1,2}$ & .13 & 2.481 & .30 \\
\hline 4. Transcendent & $252(37 \%)$ & 3.83 & .04 & 3.89 & .03 & 3.591 & .08 & $3.521,2$ & .07 & 2.631 & .09 \\
\hline 5. Highly transcendent & $29(4 \%)$ & 4.60 & .11 & 4.88 & .03 & 3.861 & .33 & 3.50 & .27 & 2.77 & .39 \\
\hline$\chi^{2}$ & & & & & & \multicolumn{2}{|c|}{8.77} & \multicolumn{2}{|c|}{$13.06 * *$} & \multicolumn{2}{|c|}{$10.09^{*}$} \\
\hline
\end{tabular}

Note: $N=684$. All analyses were run using the 3-step ML (DU3STEP) command in Mplus. The values for the outcomes are mean values for each profile. Subscripts indicate profiles that are significantly different at $p<.05$. The $\chi^{2}$ indicates the significance of the overall difference test.

$* p<.05, * * p<.01$ 


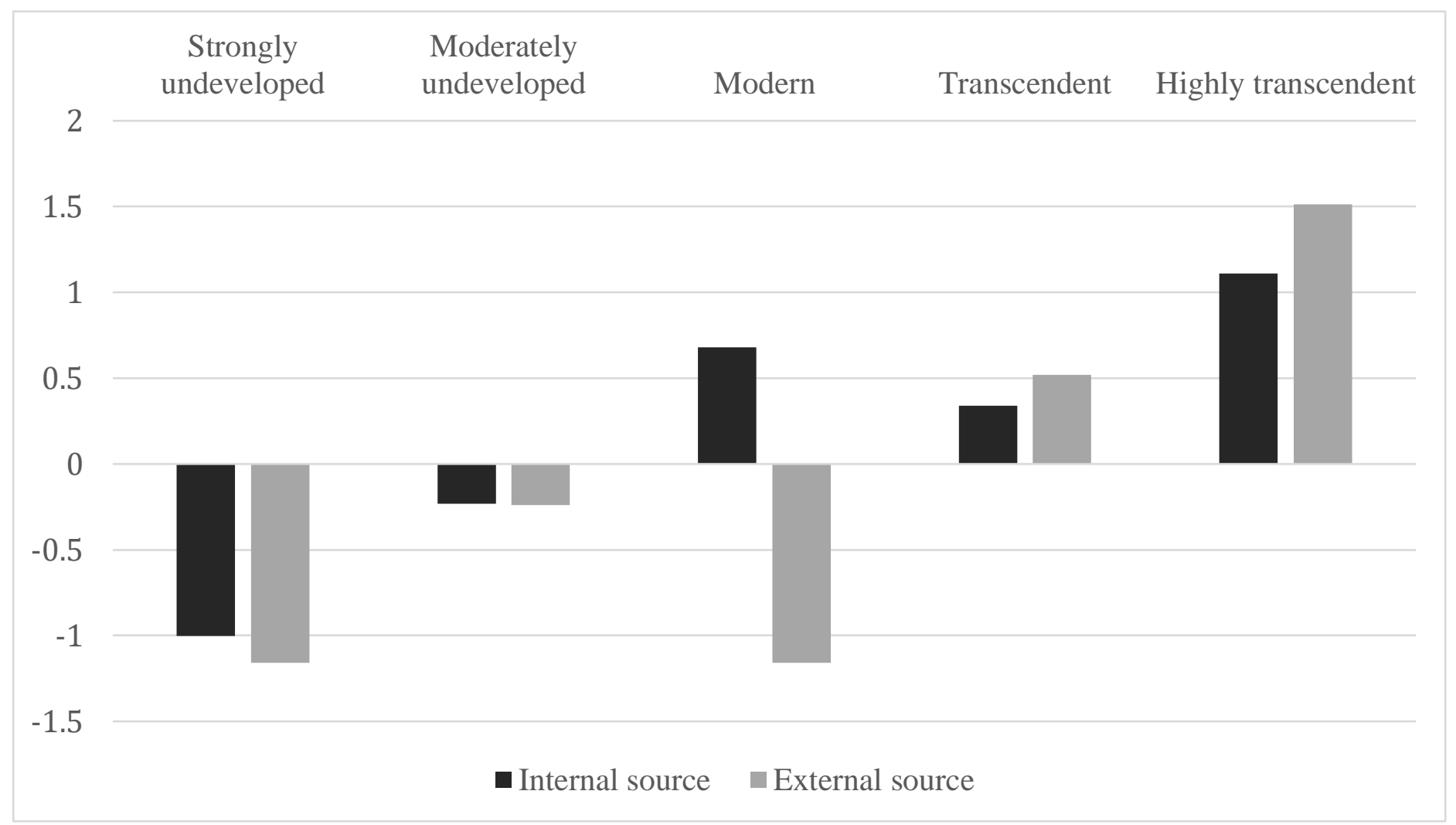

Figure 1. Latent Profiles with Sources of Calling as Profile Indicators. 